\title{
Comparison of morbidity associated with non-descent vaginal hysterectomy and total abdominal hysterectomy
}

\author{
Ranjita Ghadei, Gupteswar Mishra*
}

Department of Obstetrics and Gynecology, SCB Medical College, Cuttack, Odisha, India

Received: 04 February 2018

Accepted: 07 March 2018

\section{*Correspondence:}

Dr. Gupteswar Mishra,

E-mail: drgupteswar.mishra@gmail.com

Copyright: () the author(s), publisher and licensee Medip Academy. This is an open-access article distributed under the terms of the Creative Commons Attribution Non-Commercial License, which permits unrestricted non-commercial use, distribution, and reproduction in any medium, provided the original work is properly cited.

\begin{abstract}
Background: In the present scenario of importance non-invasive surgery, there is increase in interest and requirement of vaginal hysterectomy for non-prolapsed uterus, i.e. non-descent vaginal hysterectomy (NDVH) due to its scarless surgery. it has much more advantages than that of abdominal hysterectomy in term of cosmesis, lesser duration of surgery, lesser intraoperative complication, lesser post-operative morbidity and early resumption to work. The aim of the present study is to asses and compare various factors like duration of surgery, intraoperative blood loss, intraoperative and postoperative complication postoperative morbidities, pain perception on $3^{\text {rd }}$ post-operative day, post-operative ambulation, duration of hospital stay, time taken to resume normal work, follow up complains and afterall to decide the appropriate route of hysterectomy for benign conditions.

Methods: Hundreds of patients were selected as per the criteria. They were divided into two groups NDVH (nondescent vaginal hysterectomy) and TAH (total abdominal hysterectomy) according to the inclusion criteria. Above mentioned factors are compared between the two groups.

Results: Duration of surgery, intraoperative blood loss, intraoperative complications, post-operative morbidities and complications, duration of hospital stay, time required to resume normal work are less in NDVH group.

Conclusions: Non-descent vaginal hysterectomy is a better alternative to abdominal hysterectomy for benign conditions.
\end{abstract}

Keywords: Abdominal hysterectomy, Non-descent vaginal hysterectomy

\section{INTRODUCTION}

The term "hysterectomy" comes from the Greek word hystera, meaning "womb", and the Greek suffix -ectomy, which comes from the Greek word ektome, meaning "a cutting out".

The treatment modalities are changing day by day according to the technologically modified procedure, which is possible due to the advent of very new and sophisticated instruments, improved skill and newer drugs. This has facilitated the changing trends in the diagnostic and therapeutic aspects of gynecology more so in hysterectomy starting from the era of Hippocrates till the present day of suture-less and robotic hysterectomy and day care surgery.

Traditionally abdominal and vaginal hysterectomies represent the most and least invasive techniques respectively. The ease and convenience offered by a large abdominal incision have led to the preponderance of abdominal hysterectomy over the vaginal route.

Non-descent vaginal hysterectomy gives the benefits of minimal invasive techniques like shorter duration, less handling, less morbidity, earlier recovery, best cosmetic 
and low cost benefit. Vaginal hysterectomy has been made easy, accessible and visible even in larger nonprolapsed uteri by newer (electrocautery) technique. ${ }^{1}$

Abdominal hysterectomy remains the predominant method of uterine removal in the United States, despite evidence that vaginal hysterectomy offers advantages in regard to operative time, complication rates, return to normal activities, and overall cost of treatment. ${ }^{2}$

A Cochrane database systemic review concluded that vaginal hysterectomy rather than abdominal should be performed whenever feasible to reduce complications, hospital stay and accelerate the patient's return to normal activities. $^{3}$

The factors considered to be contra-indications for nondescent vaginal hysterectomy and common belief that bigger, bulky uterus, presence of endometriosis, Pelvic inflammatory disease, previous surgeries, and narrow vagina make vaginal hysterectomy difficult to be performed, are now not can be successfully attempted in all these conditions. ${ }^{4}$

There is an increase in the use of Vaginal hysterectomies from 12 to $34 \%$, a decrease in the use of abdominal hysterectomies and a consistent number of laparoscopic hysterectomies. ${ }^{5}$

In this centre, hysterectomy is performed by laparoscopic, abdominal and vaginal routes. However, due to the vast majority of cases being performed by the latter two methods, the comparison in this study is between vaginal and abdominal hysterectomies.

The aim of the present study was to evaluate the most efficient route of hysterectomy in women with mobile non-prolapsed uteri of size 12 weeks or lesser by comparing the intra-operative parameters, post-operative parameters and follow up parameters such as follow up complaints and psychosexual problems.

\section{METHODS}

The present study is a prospective observational study, conducted in the Department of Obstetrics and Gynaecology SCB Medical College and Hospital, Cuttack during the period August 2016 to July 2017. One hundred patients requiring hysterectomy for gynecological disorders without prolapse and without any malignancy were included in the study. Among 100 patients, fifty patients who underwent hysterectomy by vaginal route were taken as study group $\mathrm{A}$, and the remaining fifty patients that underwent hysterectomy by the abdominal route, were taken as study group $\mathrm{B}$. The standard protocol for NDVH (non-descent vaginal hysterectomy) and TAH (total abdominal hysterectomy) was followed and intra-operative parameters such as (intra-operative blood loss, time taken for surgery; intraoperative injury), post-operative parameters such as (postoperative bleeding needing laparotomy; postoperative blood transfusion; post-operative vaginal discharge; morbidities during the postoperative period; pain perception on $3^{\text {rd }}$ post op day; wound infection; any other infection; duration of hospital stay; and follow up parameters such as follow up complaints and psychosexual problems were compared.

\section{Statistical analysis}

The data collected was entered in Microsoft excel 2007 and analyzed by using SPSS version 20 . The quantitative data was expressed by mean and standard deviation. Differences in means between the group were determined by unpaired sample t-test or Mann-Whitney U-test wherever applicable. The qualitative data was expressed in percentages and the differences between percentages were computed using $\chi^{2}$ test or Fischer exact test. $P$ value less than 0.05 was considered statistically significant.

\section{RESULTS}

Current study included 100 patients in total and divided them to two groups in equal proportion. One group undergone non- descent vaginal hysterectomy (NDVH group) and other group undergone total abdominal hysterectomy (TAH Group). Both the group had 50 patent each.

The mean age of the study participant in NDVH group was $48.04 \pm 6.08$ and in TAH group it was $47.60 \pm 6.76$. This difference in mean age was not statistically significant $(\mathrm{p}$ value $=0.733$ ) or we can say that both groups were comparable with age distribution (Table 1). When age was categorized into groups it was found that almost similar proportion of study participant were in $<45$ years $(30 \%$ Vs $34 \%), 45-55$ years $(58 \%$ Vs $52 \%)$ and $\geq 55$ years (12\% vs 14\%). This difference in proportion were also not statistically significant ( $\mathrm{p}$ value $=0.833$ ).

Table 1: Baseline characteristics of the study participants.

\begin{tabular}{|c|c|c|c|c|}
\hline Variable & $\begin{array}{l}\text { NDVH } \\
\text { N (\%) }\end{array}$ & $\begin{array}{l}\text { TAH } \\
\text { N }(\%)\end{array}$ & $\begin{array}{l}\text { Total } \\
\text { N }(\%)\end{array}$ & $\begin{array}{l}\text { P } \\
\text { value* }\end{array}$ \\
\hline \multicolumn{5}{|c|}{ Age group (years) } \\
\hline$<45$ & $15(30.0)$ & $17(34.0)$ & $32(32.0)$ & \multirow{3}{*}{0.833} \\
\hline $45-55$ & $29(58.0)$ & $26(52.0)$ & $55(55.0)$ & \\
\hline$\geq 55$ & $6(12.0)$ & $7(14.0)$ & $13(13.0)$ & \\
\hline \multicolumn{5}{|l|}{ Parity } \\
\hline Primipara & $1(2.0)$ & $1(2.0)$ & $2(2.0)$ & \multirow{3}{*}{0.605} \\
\hline $2-3$ & $41(82.0)$ & $37(74.0)$ & $78(78.0)$ & \\
\hline$\geq 4$ & $8(16.0)$ & $12(24.0)$ & $20(20.0)$ & \\
\hline \multicolumn{5}{|l|}{ Residence } \\
\hline Rural & $42(84.0)$ & $38(76.0)$ & $80(80.0)$ & \multirow{2}{*}{0.317} \\
\hline Urban & $8(16.0)$ & $12(24.0)$ & $20(20.0)$ & \\
\hline
\end{tabular}

*Chi-squared test was used

Table 1 show that with respect to parity, equal percentage of patients were primipara $(2 \%)$, maximum percentage 
falls under parity 2 or 3 (NDVH $82 \%$ Vs TAH 74\%) without any statistical significance $(p$ value $=0.605)$. Table 1 shows that with respect to place of residence most of the study participant belonged to rural area $(80$ $\%$ ). Among them $84 \%$ in NDVH group and $76 \%$ in TAH group belonged to rural area.

Table 2: Presenting complain of the study participants.

\begin{tabular}{|llll|}
$\begin{array}{l}\text { Clinical } \\
\text { characteristics }\end{array}$ & $\begin{array}{l}\text { NDVH } \\
\text { N } \%)\end{array}$ & $\begin{array}{l}\text { TAH } \\
\text { N }(\%)\end{array}$ & $\begin{array}{l}\text { Total } \\
\text { N }(\%)\end{array}$ \\
\hline $\begin{array}{l}\text { Bleeding per } \\
\text { vaginum }\end{array}$ & $1(2.0)$ & $2(4.0)$ & $3(3.0)$ \\
\hline Polymenorrhagia & $4(8.0)$ & $4(8.0)$ & $8(8.0)$ \\
\hline Dysmenorrhagia & $0(0)$ & $1(2.0)$ & $1(1.0)$ \\
\hline Menorrhagia & $35(70.0)$ & $31(62.0)$ & $66(66.0)$ \\
\hline Menometrorrhagia & $1(2.0)$ & $0(0)$ & $1(1.0)$ \\
\hline Pain abdomen & $8(16.0)$ & $2(4.0)$ & $10(10.0)$ \\
\hline Mass Abdomen & $0(0)$ & $10(20.0)$ & $10(10.0)$ \\
\hline White Discharge & $1(2.0)$ & $0(0)$ & $1(1.0)$ \\
\hline
\end{tabular}

Table 2 and shows that majority of the study participants have menorrhagia as the presenting complain in both the groups.

Pap smear examination showed that equal number of participant have abnormal finding (30\%) in NDVH group and TAH Group with no statistical difference ( $p$ value $=1.00$ ). Most of the abnormal pap-smear were inflammatory in nature and only one patient in NDVH group had cervicitis as the abnormal finding.

Mean uterine size of the study participant in NDVH group was $8.6 \pm 2.04$ whereas in TAH group it was $9.40 \pm 2.68$ weeks. This difference was not statistically significant $(\mathrm{p}$ value $=0.135)$.

Table 3: Pre-operative diagnosis of the condition among the study participants.

\begin{tabular}{|llllll|}
\hline NDVH & \multicolumn{7}{l|}{ TAH } \\
\hline Diagnosis & No. & \% & Diagnosis & No. & $\%$ \\
\hline AUB A & 9 & 18 & AUB & 4 & 8 \\
\hline AUB E & 15 & 30 & AUB A & 5 & 10 \\
\hline AUB L & 20 & 40 & AUB P & 3 & 6 \\
\hline AUB O & 1 & 2 & AUB L & 22 & 42 \\
\hline AUB P & 3 & 6 & Ovarian cyst & 11 & 22 \\
\hline $\begin{array}{l}\text { M. } \\
\text { hemorrhagica }\end{array}$ & 1 & 2 & $\begin{array}{l}\text { Adenexal } \\
\text { mass }\end{array}$ & 4 & 8 \\
\hline Cervicitis & 1 & 2 & $\begin{array}{l}\text { Placental } \\
\text { site GTD }\end{array}$ & 1 & 2 \\
\hline & & & PMB & 1 & 2 \\
\hline
\end{tabular}

Table 3 shows the pre- operative diagnosis of the study participants. In the NDVH group, most of the study participants were having abnormal uterine bleeding (96\%). Although most of the study subjects in TAH group were suffering from AUB $(68 \%)$ but $22 \%$ were also suffering from Ovarian cyst (22\%), and few of them also suffered from adenexal mass $(8 \%)$ or placental site GTD $(2 \%)$ or PMB $(2 \%)$.

Table 4: Histopathological diagnosis.

\begin{tabular}{|c|c|c|c|c|c|}
\hline \multicolumn{3}{|l|}{ NDVH } & \multicolumn{3}{|l|}{ TAH } \\
\hline Diagnosis & No. & $\%$ & Diagnosis & No. & $\%$ \\
\hline Adenomyoma & 9 & 18 & Adenomyoma & 8 & 16 \\
\hline Cervicitis & 1 & 2 & $\begin{array}{l}\text { Myometrial } \\
\text { hyperplasia }\end{array}$ & 1 & 2 \\
\hline $\begin{array}{l}\text { Endometrial } \\
\text { hyperplasia }\end{array}$ & 16 & 32 & $\begin{array}{l}\text { Endometrial } \\
\text { hyperplasis }\end{array}$ & 4 & 8 \\
\hline Leiomyoma & 19 & 38 & Leiomyoma & 25 & 50 \\
\hline $\begin{array}{l}\text { Metropathia } \\
\text { haemorrhagica }\end{array}$ & 1 & 2 & Polyp & 2 & 4 \\
\hline \multirow[t]{5}{*}{ Polyp } & 4 & 8 & $\begin{array}{l}\text { Mucinous } \\
\text { cyst adenoma }\end{array}$ & 1 & 2 \\
\hline & & & Simple cyst & 11 & 22 \\
\hline & & & Complex cyst & 2 & 4 \\
\hline & & & $\begin{array}{l}\text { Chocolate } \\
\text { cyst }\end{array}$ & 1 & 2 \\
\hline & & & $\begin{array}{l}\text { Placental site } \\
\text { GTD }\end{array}$ & 1 & 2 \\
\hline
\end{tabular}

Histopathological diagnosis in the NDVH group was shown in table 4. Most of the study participants in NDVH group were diagnosed to have leiomyoma (38\%) followed by endometrial hyperplasia (32\%). Other diagnoses were shown in table 4. Histopathological diagnosis in the TAH group was shown in table 4. Most of the study participants in TAH group were diagnosed to have leiomyoma $(50 \%)$ followed by simple cyst $(22 \%)$ and adenomyoma (16\%), Other diagnoses were, polyp, cystadenoma, endometrial hyperplasia, etc.

Few of the patients in both the groups were suffering from some chronic condition. Equal percentages of the study participants in both the groups were suffering from diabetes (6\%), hypertension $(6 \%$ vs $8 \%)$ and hypothyroidism ( $1 \%$ vs $3 \%)$, which is not statistically Significant. ( $\mathrm{p}$ value $>0.05$ )

Table 5: Comparison of intraoperative factors in both the groups.

\begin{tabular}{|lllllll|}
\hline $\begin{array}{l}\text { Intraoperative } \\
\text { factors }\end{array}$ & NDVH & TAH & & P \\
\hline Duration (min) & 74.60 & 15.67 & 82.30 & 15.75 & 0.016 \\
\hline Blood loss (ml) & 155.00 & 43.15 & 214.00 & 55.36 & $<0.001$ \\
\hline Pain perception & 2.72 & 0.757 & 6.20 & 1.03 & $<0.001$ \\
\hline
\end{tabular}

Table 5 shows the comparison of different intra-operative factors in both the groups. Duration of the surgery was $82.30 \pm 15.75$ minutes in TAH group which was significantly higher as compared to NDVH group $(74.60 \pm 15.67)$ ( $\mathrm{p}$ value $=0.016)$. Blood loss was also higher in TAH group $(214.00 \pm 55.36)$ as compared to 
NDVH group $(155 \pm 43.15)$ which was statistically significant (p value <0.001). It was also found significantly higher mean pain perception score in TAH group compared to NDVH group ( $\mathrm{p}$ value $<0.001$ ).

Table 6: Comparison of post-operative criteria in both the groups.

\begin{tabular}{|llllll|}
\hline $\begin{array}{l}\text { post- } \\
\text { operative } \\
\text { criteria }\end{array}$ & Mean & SD & Mean & SD & $\begin{array}{l}\text { P } \\
\text { value* }\end{array}$ \\
\hline $\begin{array}{l}\text { Post-op } \\
\text { ambulation } \\
\text { (days) }\end{array}$ & 28.40 & 11.40 & 53.00 & 11.69 & $<0.001$ \\
\hline $\begin{array}{l}\text { Hospital stay } \\
\text { (days) }\end{array}$ & 5.10 & 0.30 & 7.28 & 0.92 & $<0.001$ \\
\hline $\begin{array}{l}\text { Resumption of } \\
\text { work (days) }\end{array}$ & 11.46 & 1.54 & 17.38 & 2.84 & $<0.001$ \\
\hline $\begin{array}{l}\text { Haemoglobin } \\
\text { changes (gm) }\end{array}$ & 1.23 & 0.439 & 1.21 & 0.419 & 0.896 \\
\hline
\end{tabular}

*Mann-Whitney U test was used

Duration of hospital stay, post-operative ambulation and resumption of work following surgery were highly significantly higher in TAH group as compared to NDVH group.

Table 6 shows comparison of these factors. Postoperative haemoglobin changes did not show any statistical significant difference in NDVH group compared to TAH group ( $\mathrm{p}$ value $=0.896)$. Postoperative blood transfusion was required in three patients in NDVH group whereas in TAH group it was required for 6 patients. This difference was not statistically significant $(\mathrm{p}$ value $=0.486)$.

Table 7: Post-operative morbidity and complications in both the groups.

\begin{tabular}{|c|c|c|c|}
\hline Complication & $\begin{array}{l}\text { NDVH } \\
\mathbf{N}(\%)\end{array}$ & $\begin{array}{l}\text { TAH } \\
\text { N }(\%)\end{array}$ & P value $*$ \\
\hline \multicolumn{4}{|c|}{ Wound infection } \\
\hline Present & $0(0)$ & $3(6.0)$ & \multirow{2}{*}{0.242} \\
\hline Absent & $50(100)$ & $47(44.0)$ & \\
\hline \multicolumn{4}{|c|}{ Vaginal discharge } \\
\hline Present & $5(10)$ & $4(8)$ & \multirow{2}{*}{0.645} \\
\hline Absent & $45(90)$ & $46(92)$ & \\
\hline \multicolumn{4}{|c|}{ Post- operative morbidity } \\
\hline Present & $6(12)$ & $12(24)$ & \multirow{2}{*}{0.113} \\
\hline Absent & $44(88)$ & $38(76)$ & \\
\hline
\end{tabular}

*Chi-squared test was used

Table 7 show the distribution of different post-operative morbidity in both the groups respectively. Different postoperative morbidity found in both the study groups were fever ( $2 \%$ vs $12 \%)$, headache $(0 \%$ vs $2 \%)$, paralytic ileus ( $0 \%$ vs $2 \%)$, urinary tract infection (4\% vs $4 \%)$ and vomiting (4\% vs 4\%), which is not statistically significant ( $\mathrm{p}$ value $>0.05$ ).
Table 8: comparison of follow up complains (pain abdomen, vaginal discharge) in both the groups.

\begin{tabular}{|llll|}
\hline Follow up & NDVH & TAH & P value* \\
complains & N $(\%)$ & N $(\%)$ & \\
\cline { 1 - 3 } Present & $10(20)$ & $14(28)$ & 0.348 \\
\hline Absent & $40(80)$ & $36(72)$ & \\
\hline
\end{tabular}

*Chi-squared test was used

With regards to follow up complaints vaginal discharge were found more in NDVH group (10\%) as compared to TAH group $(8 \%)$. Pain abdomen were considerably more in TAH group $(20 \%)$ as compared to NDVH group $(10 \%)$, which is not statistically significant ( $\mathrm{p}$ value $>0.05$ ) (Table 8).

In the present study there is no intra-operative complication, so there is no need for conversion to laparotomy in NDVH group, there is no need of laparotomy for post-operative complications. In this study Mortality rate was also nil in both the study groups. In this study there is no evidence of psychosexual problem in both the study groups.

\section{DISCUSSION}

Current study was a non- randomized prospective study to understand the efficacy in terms of peri-operative factors associated with two surgical techniques i.e. nondescendent vaginal hysterectomy with the total abdominal hysterectomy. The study also aimed to compare the complications associated with both the surgical procedures.

In this study author had included 50 participants in each study arm i.e. non- descendent vaginal hysterectomy (NDVH) group and the total abdominal hysterectomy (TAH) group. Comparison of baseline characteristics showed that both the groups were comparable. Present study finding did not show any statistically significant difference in the various socio-demographic factors like age and place of residence which eliminated the confounding factors in both the groups. Our study was similar to other studies like Hwang et al, Ribeiro et al, Silva-Filho et al, which showed mean age of 45 years, 42.3 years, 45 years respectively..$^{6-8}$

Similarly, in terms of clinical and obstetrics history both the groups did not show any statistically significant difference. Proportion of study subjects in different parity groups like primi-para, Para 2 to 3 and more than 3 were almost similar. This is comparable to the study by Bharatnur S et al, which had mean parity of 3.8 and 3.6 in TAH and NDVH group respectively. ${ }^{9}$ Pap-smear finding and uterine size at the time of admission in both the groups were also similar which shows that our selection of samples in each group were comparable in terms of baseline clinical findings. In the present study mean uterine size in gestational weeks was 9.40 weeks in TAH and 8.68 weeks in NDVH and this is comparable to the 
study of Miskry T et al, which had 7.8 weeks in NDVH as compared to 6.9 weeks in TAH group. ${ }^{10}$

With respect to diagnosis, we found differences in preoperative, and histopathological diagnoses. These different diagnoses are uniformly distributed in this study population. Mehta et al, in their study found fibroids were the most common indication in both the groups and DUB was the second most common indication in both thegroups. $^{11}$ Similarly, Shanthini et al, also found Dysfunctional uterine bleeding was the most common indication for both TAH and NVDH. ${ }^{12}$ Present study also found abnormal uterine bleeding as one of the common indication for NDVH and TAH which was similar to the above mentioned study. The preoperative diagnosis is the presumptive diagnosis, and the histopathological diagnosis are the confirmatory diagnoses. Since there is a margin of error in clinical diagnosis and confirmatory diagnosis (like histopathological diagnoses), these difference in diagnoses are expected. For all the conditions for which patients were admitted to the hospital, the method of treatment was the same i.e. hysterectomy. Since we are comparing the different approaches of the same treatment i.e. hysterectomy, it should not affect the study findings.

Since the primary objective was to find the difference in efficacy of treatment procedures i.e. NDVH and TAH, we had compared various factors associated with efficacy like duration of surgery, blood loss during surgery, pain perception of the patients after surgery, duration of hospital stay, post-operative ambulation and complications etc. in both the procedures.

The current study found that the duration of surgery was higher in TAH group (82.30 \pm 15.75$)$ minutes as compared to NDVH group $(74.60 \pm 15.67)$ minutes. The mean duration of surgery was significantly less among Nondescent vaginal hysterectomy as compared to Total abdominal hysterectomy cases in the study group. Similar finding observed in a study conducted by Chen B et al. 2014, the operation time in Vaginal hysterectomy (Mean time $65.2 \mathrm{~min}$ ) group was significantly shorter than in the abdominal hysterectomy (Mean time $95.6 \mathrm{~min}$ ) group. ${ }^{13}$ Bharatnur $\mathrm{S}$ et al, also noted that mean operating time was more in abdominal hysterectomy than in vaginal hysterectomy (AH $101 \pm 27.1$ min, $\mathrm{VH} \quad 65 \pm 26.2) .{ }^{9}$ Operative time in study conducted by Mehta et al, was less in NDVH compared to TAH $(69.84 \pm 14.06 \mathrm{~min}$. v/s $77.64 \pm 12.92 \mathrm{~min}$ ) and this is comparable to studies. ${ }^{11}$ Other studies (Benassi L et al, Raju VS et al, David S et al) also found similar findings comparable to this study. ${ }^{14-}$ 16

Mean blood loss was significantly less amongst Nondescent vaginal hysterectomy cases as compared to Total abdominal hysterectomy. In our study mean blood loss was $155 \mathrm{ml}$ in Non-descent vaginal and $214 \mathrm{ml}$ in Total abdominal hysterectomy. Bing Chen et al, who compared outcomes of vaginal and abdominal hysterectomy procedures in women also concurred with their results showing intraoperative blood loss was significantly less in the Vaginal Hysterectomy (Mean 30.4ml) group compared with the abdominal hysterectomy (Mean 70.3 ml) group. ${ }^{13}$ Other studies conducted by Ribeiro et al and Alokananda $\mathrm{R}$ et al also found significantly lesser blood loss in Non-descent vaginal hysterectomy as compared to Total abdominal hysterectomy which was similar to our study finding. ${ }^{7,17}$

In the present study, pain perception score was calculated by Visual Analogue Scale and the mean pain perception score on $3^{\text {rd }}$ post-operative day was 2.72 for NDVH group and 6.20 for TAH group, difference being statistically highly significant ( $\mathrm{p}<0.001)$. In a study conducted by Mirza et al 2016, they found that the pain score on visual analogue scale on third postoperative day was found significantly less in NDVH group as compared to TAH group with the $\mathrm{p}$ value of $0.002 .{ }^{18}$ Although, we have not calculated the mean number of analgesic doses required in each of the surgery but it can be a proxy measure for our study finding. Various studies in the past have also confirmed that patients undergoing vaginal hysterectomy have reduced analgesic requirements when compared with patients undergoing TAH. This not only added to comfort of patients undergoing NDVH but also to the cost effectiveness and early discharge of patients in this group by Miskry T et al, Benassi L et al, Dawood NS et al. ${ }^{10,14,19}$

Post-operative haemoglobin level changes were similar in this study (1.23 Vs 1.21) gm\%. A study conducted by Virmani $\mathrm{S}$ et al, found that the mean pre-operative haemoglobin level for the two groups NDVH and TAH was $11.802 \mathrm{gm} \%$ and $12.006 \mathrm{gm} \%$ respectively. The mean post-operative haemoglobin level for NDVH group was $10.59 \mathrm{gm} \%$ and for the TAH group was $10.2 \mathrm{gm} \%$. Further analysis of the study by Virmani et al revealed that there was a change of $1.21 \mathrm{gm} \%$ change in haemoglobin level in NDVH group which the change was $1.80 \mathrm{gm} \%$ in TAH group which was not statistically significant. $^{20}$ This study finding by Virmani et al was similar to our study. In the past, a study carried out by Kayastha $\mathrm{S}$ et al, showed a similar result indicating that NDVH is a relatively safe procedure in terms of postoperative haemoglobin changes compared to TAH group. even in enlarged uteri. $^{21}$

In the current study, post-operative blood transfusion was required for lesser number of patients in NDVH group compared to TAH group. A study conducted by Mehta K et al, found $8 \%$ cases of TAH and $4 \%$ cases of NDVH required one unit of blood transfusion post-operatively which was similar to our study finding. ${ }^{11}$

In the present study, the most common complication among both the groups was fever. Different postoperative morbidity found in both the study groups were fever in the TAH and NDVH groups ( $2 \%$ vs $12 \%)$, headache $(0 \%$ vs $2 \%)$, paralytic ileus $(0 \%$ vs $2 \%)$, urinary 
tract infection (4\% vs 4\%)and vomiting (4\% vs $4 \%$ ). Garg, et al.2002,reported more febrile morbidity in TAH group $(17.6 \%)$ compared to NDVH group (11.5\%) similar to our findings. ${ }^{22}$ Mehta $\mathrm{K}$ et al, reported fever in $10 \%$ vs $4 \%$ cases, UTI in $2 \%$ vs $4 \%$ cases, and paralytic ileus in $6 \%$ vs nil cases in TAH and NDVH group respectively. ${ }^{11}$ Chavhan RP et al, reported fever in $24 \%$ vs $16 \%$ cases, UTI in $4 \%$ vs $8 \%$ cases, paralytic ileus in $8 \%$ vs nil in TAH and NDVH group respectively. ${ }^{23}$ Abrol $\mathrm{S}$ et al, reported fever in $26 \%$ vs $6 \%$ cases, UTI in $6 \%$ vs $2 \%$ cases,and paralytic ileus in $6 \%$ vs nil in TAH and NDVH group respectively. ${ }^{24}$

In the present study, author found wound infection rate in the TAH group to be $6 \%$ with no cases in NDVH group. Chakraborthy et al, and Shantini et al reported a wound infection rate of $5 \%$ and $5.7 \%$ respectively in TAH group which was similar to our study finding. ${ }^{12,25}$ The reason behind higher rates of infection can be, as TAH is a more extensive operation, wound infection chances are more if proper wound care was not taken.

Mean hospital stay in days was significantly less among Non-descent vaginal hysterectomy as compared to Total abdominal hysterectomy. Mean hospital stay was 5.10 days in Non-descent vaginal hysterectomy and 7.28 days in Total abdominal hysterectomy. Similar finding observed in a study conducted by Chen B et al,with hospital stay length in the vaginal hysterectomy group (Mean hospital stay 4.5 days) being significantly shorter than in the Abdominal hysterectomy group (Mean hospital stay 6.3 days). ${ }^{13}$ According to study conducted by Balakrishnan $\mathrm{D}$ et al, the mean length of hospital stay was 10.87 days in the abdominal group while the mean length of hospital stay was 4.67 days in the vaginal group. They also found that mean time to post-operative mobility in the vaginal hysterectomy group were significantly shorter and less severe respectively than those in the abdominal group $(\mathrm{p}<0.05) .{ }^{26}$ This study finding was also similar to this study finding.

Johnson $\mathrm{N}$, included twenty-seven trials that included 3643 participants. Independent selection of trials and data extraction were employed following Cochrane guidelines. They found that the benefits of Vaginal hysterectomy versus Abdominal hysterectomy was shorter duration of hospital stay (WMD 1.0 day, $95 \%$ CI 0.7 to 1.2 days). ${ }^{1}$

In this current study, resumption to normal work following surgery were (11.4days vs. 17.3days) in NDVH and TAH group respectively, which is higher in the TAH group as compared to the NDVH group. Johnson $\mathrm{N}$, Cochrane Systematic Review also found that the benefits of vaginal hysterectomy versus Abdominal hysterectomy was speedier return to normal activities (WMD 9.5 days, $95 \%$ CI 6.4 to 12.6 days $)^{1}$.

All the patients were followed for 3 months. In the present study women were advised to come after 6 weeks for follow up. They had been counselled about surgical amenorrhea and in case of oophorectomy, they were counselled about the post-menopausal symptoms. With regards to follow up complains vaginal discharge was found more in NDVH group (10\%) as compared to TAH group (8\%). Abrol S et al, reported vaginal discharge in one case $(2 \%)$ in each group. ${ }^{24}$

In this study pain abdomen were considerably more in TAH group (20\%) as compared to NDVH group (10\%). In the present study there were no intra-operative complications in either group, there was no need for conversion to laparotomy in NDVH group and also there was no need of laparotomy for post-operative complications. Kafy $\mathrm{S}$ et al, in the CREST study reported a bowel injury of $0.4 \%$ with vaginal hysterectomy. Conversion rates of $0.4 \%$ from vaginal to abdominal approach have been reported in a retrospective review of 220 patients. $^{27}$

Sahin $\mathrm{Y}$ et al, reported in their study that the main intraoperative complication of the 241 vaginal hysterectomies was bladder injury that occurred in 1 case $(0.4 \%)$ in the $<280$-g group. ${ }^{28}$ Chakraborty $\mathrm{S}$ et al reported one case of bladder injury in NDVH group. ${ }^{25}$ Chavhan RP et al, stated that there is one case of bowel injury in TAH group. $^{23}$

Mehta $\mathrm{K}$ et al, reported one case of bladder injury in NDVH group and one case of bowel injury in TAH group and 4 cases of ureteric injury in TAH group. ${ }^{11}$

In this study, the Mortality rate was also nil in both the study groups. In this study, there was no evidence of psychosexual problems in both the study groups. The present study was undertaken to provide objective evidence to assist Gynaecological surgeons in their selection of the most appropriate method of hysterectomy and to provide data to permit patients to make an informed decision about their preferred type of hysterectomy. Present study findings strongly support non-descent vaginal hysterectomy. Hence, in this orientation, the study supports the fact that NDVH being a minimally invasive procedure should be the technique of choice in routine practice.

\section{CONCLUSION}

However, further evaluation in a larger population needs to be done for an even better generalisation of the findings.

\section{ACKNOWLEDGMENTS}

Authors would like to thank the faculties, doctors and staffs of Department of Obstetrics and Gynaecology, SCB, Medical College, Cuttack, Odisha for their support while conducting this study.

Funding: No funding sources

Conflict of interest: None declared 
Ethical approval: The study was approved by the Institutional Ethics Committee

\section{REFERENCES}

1. Johnson N, Barlow D, Lethaby A. Surgical approach to hysterectomy for benign gynecological disease. Cochrane Database Syst Rev. 2005;(1):CD003677.

2. Wu JM, Wechter ME, Geller EJ, Nguyen TV, Visco AG. Hysterectomy rates in the United States, 2003. Obstet Gynecol. 2007;110(5):1091-5.

3. Johnson N, Barlow D, Lethaby A. Surgical approach to hysterectomy for benign gynecological disease. Cochrane Database Syst Rev. 2009(3):CD003677.

4. Coulam CB, Pratt JH. Vaginal hysterectomy: is previous pelvic operation a contraindication. Am J Obstet Gynecol. 1973;116:252.

5. Nielsen SL, Daugbjerg SB, Gimbel H, Settnes A. Steering committee of Danish Hysterectomy Database Use of vaginal hysterectomy in Denmark; rates indications and patient characteristics. Acta Obstet Gynecol Scand. 2011;90990:978-84.

6. Hwang JL, Seow KM, Tsai YL, Huang LW, Hsieh BC, Lee C. Comparative study of vaginal, laparoscopically assisted vaginal and abdominal hysterectomies for uterine myoma larger than $6 \mathrm{~cm}$ in diameter or uterus weighing at least $450 \mathrm{~g}$ : a prospective randomized study. Acta obstetricia et gynecologica Scand inavica. 2002;81(12):1132-8.

7. Ribeiro SC, Ribeiro RM, Santos NC, Pinotti JA. A randomized study of total abdominal, vaginal and laparoscopic hysterectomy. Int $\mathbf{J}$ Gynecol Obstet. 2003;83(1):37-43.

8. Silva-Filho AL, Werneck RA, de Magalhães RS, Belo AV, Triginelli SA. Abdominal vs vaginal hysterectomy: a comparative study of the postoperative quality of life and satisfaction. Archives gynecology obstetrics. 2006;274(1):21.

9. Bharatnur S. Comparative study of abdominal hysterectomy versus vaginal hysterectomy in non descent cases. Int J Gynecol Obstet. 2010;15(2).

10. Miskry T, Magos A. Randomized, prospective, doubleblind comparison of abdominal and vaginal hysterectomy in women without uterovaginal prolapse. Acta obstetricia et gynecologica Scandinavica. 2003;82(4):351-8.

11. Mehta K, Prakash O, Fatehpuriya DS, Verma L. Comparative study of abdominal hysterectomy and vaginal hysterectomy in non-descent cases a prospective study. Int $\mathbf{J}$ Reprod Contracept Obstet Gynecol. 2017;6:1265-70.

12. Shanthini NF, Poomalar GK, Jayasree M, Bupathy A. Evaluation of complications of abdominal and vaginal hysterectomy. Int $\mathrm{J}$ Reprod Contraception Obstet Gynaecol. 2012;1(1):7-11.

13. Chen B, Ren DP, Li JX, Li CD. Comparison of vaginal and abdominal hysterectomy: A prospective nonrandomized trial. Pak J Med Sci. 2014;30:875-9.

14. Benassi L, Rossi T, Kaihura CT, Ricci L, Bedocchi L, Galanti B, et al. Abdominal or vaginal hysterectomy for enlarged uteri: a randomized clinical trial. Am J Obstet Gynecol. 2002;187(6):1561-5.

15. Raju VS, Girija BS. Comparison of vaginal hysterectomy for non-descent uterus with abdominal hysterectomy. Indian J Public Health Res Develop. 2014;5(1):15.

16. Soriano D, Seidman D, Hwang JL, Seow KM, Tsai YL, Huang LW, Hsieh BC, Lee C. Vaginal hysterectomy for large fibroids had reduced operating time and hospital stay compared to abdominal hysterectomy. Evidencebased Obstet Gynecol. 2004 Mar;6(1).

17. Aloknanda R, Luna P, Roshan B, Chaudhary R. NonDecent Vaginal Hysterectomy: a constantly Improving Surgical Art. J Obstet Gynecol India. 2011;61(2):182-8.

18. Mirza R, Malhotra P, Kumar D, Kumar S. Abdominal Versus Vaginal Hysterectomy in Non-Descent Uterus. JK Science J. 2016;18(4):206-10.

19. Dawood NS, Mahmood R, Haseeb N. Comparison of vaginal and abdominal hysterectomy: peri- and postoperative outcome. J Ayub Med Coll Abbottabad. 2009;21(4):116-20.

20. Virmani S, Swain U. Comparative analysis of patient profile, intraoperative characteristics and postoperative outcomes of two routes of hysterectomy: non-descent vaginal hysterectomy and total abdominal hysterectomy. Int J Reprod Contracept Obstet Gynecol. 2015;4:1128-32.

21. Kayastha S, Tuladhar H. Vaginal hysterectomy vs. abdominal hysterectomy. Nepal Med Coll J. 2006;8(4):259-62.

22. Garg PK, Deka D, Malhotra N. Non-descent vaginal hysterectomy for benign condition. A better proposition than abdominal hysterectomy. J Obstet Gynecol Today. 2002;6:345-6.

23. Chavhan RP, Arora G, Pajai S. comparative study between vaginal and abdominal hysterectomy in non descent cases. Int J Sci Rep. 2016;2(3):48-52.

24. Abrol S, Rashid S, Jabeen F, Kaul S. Comparative analysis of NDVH vs TAH in benign uterine disorders. Int J Reprod contracept Obstet Gynecol. 2017;6:846-9.

25. Chakraborty S, Goswami S, Mukherjee P, Sau M. Hysterectomy, Which Route? J Obstet Gynecol Indian. 2011;61:554-7.

26. Balakrishnan D, Dibyajyoti G. A Comparison Between Non-Descent Vaginal Hysterectomy and Total Abdominal Hysterectomy. JCDR. 2016;10(1):QC11-4.

27. Kafy S, Huang JY, Al-sunaidi M. Audit of morbidity and mortality of 1792 hysterectomies. J Minim Invasive Gynecol. 2006;13:55-9.

28. Sahin Y. Vaginal hysterectomy and oophorectomy in women with 12-20 weeks' size uterus. Acta Obstet Gynecol Scand. 2007;86(11):1359-69.

Cite this article as: Ghadei $\mathrm{R}$, Mishra G.

Comparison of morbidity associated with nondescent vaginal hysterectomy and total abdominal hysterectomy. Int J Reprod Contracept Obstet Gynecol 2018;7:1554-60. 